\title{
Secondhand smoke and incidence of dental caries in deciduous teeth among children in Japan: population based retrospective cohort study
}

Table 1 in this Research paper (BMJ 2015;351:h5397, doi:10. 1136/bmj.h5397) contains some errors. Several of the listed numbers of girls and first births are incorrect in the three columns categorising infants' exposure to tobacco smoke at 4 months of age. Here are the correct values for girls and first births, respectively: $16756(48.7 \%)$ and $10835(45.7 \%)$ for infants not exposed to secondhand smoke, 18145 (48.7\%) and
12144 (49.7\%) for infants exposed to only household smoking, and 2560 (48.6\%) and 1002 (30.3\%) for infants exposed to tobacco smoke. These errors only appear in table 1 and the numbers are not referred to in the main text.

Cite this as: BMJ 2015;351:h6425

๑ BMJ Publishing Group Ltd 2015 